\title{
Genetic pattern of the recent recovery of European otters in southern France
}

\author{
Xavier Janssens, Michaël C. Fontaine, Johan R. Michaux, Roland Libois, Jean de Kermabon, \\ Pierre Defourny and Philippe V. Baret
}

X. Janssens and P. Defourny, Dept of Environmental Sciences and Land Use Planning, Unit of Geomatics, Univ. catholique de Louvain, Croix du Sud 2 box 16, BE-1348 Louvain-la-Neuve, Belgium, and Biodiversity Research Centre and Unit of Genetics (GENA-POPS), Univ. catholique de Louvain, Croix du Sud 2 box 14, BE-1348 Louvain-la-Neuve, Belgium. - M. C. Fontaine, CBGP-INRA, Campus International de Baillarguet CS 30016 Cedex, FR-34980 Montferrier-sur-Lez, France, and MARE Centre, Lab. For Oceanology, Univ. of Liège, Allée de la Chimie 3, BE-4000 Liège, Belgium. - J. R. Michaux, CBGP-INRA, Campus International de Baillarguet CS 30016 Cedex, FR-34980 Montferrier-sur-Lez, France, and Génétique des Microorganismes, Dépt des Sciences de la Vie, Univ. de Liège, Inst. De Botanique B22, BE-4000 Liège, Belgium. - R. Libois, Unit of Zoogeography, Univ. de Liège, B22, Bvd du Rectorat 27, BE-4000 Liège, Belgium. - J. de Kermabon, Service Scientifique et du Plan, Parc national des Cévennes, FR-48400 Florac, France. - P. V. Baret (baret@gena.ucl.ac.be), Biodiversity Research Centre and Unit of Genetics (GENAPOPS), Univ. catholique de Louvain, Croix du Sud 2 box 14, BE-1348 Louvain-la-Neuve, Belgium.

\begin{abstract}
We investigated how landscape affects the population genetic structure and the dispersal of the elusive European otter Lutra lutra in a contemporary colonization context, over several generations and at the level of hydrographic basins. Our study area included 10 basins located in the Cévennes National Park (CNP), at the southern front of the natural otter recovery in France. Each basin comprised 50 to $300 \mathrm{~km}$ of permanent rivers that were surveyed for otter presence from 1991 to 2005. Faecal samples collected in 2004 and 2005 in this area were genotyped at 9 microsatellite loci, resulting in the identification of 70 genetically distinct individuals. Bayesian clustering methods were used to infer genetic structure of the populations and to compare recent gene flow to the observed colonization. At the regional level, we identified 2 distinct genetic clusters (NE and SW; FST $=0.102$ ) partially separated by ridges, suggesting that the CNP was recolonized by 2 genetically distinct otter populations. At the basin level, the genetic distance between groups of individuals in different basins was positively correlated to the mean slope separating these basins. The probable origins and directions of individual movements (i.e. migration between clusters and basin colonization inside clusters) were inferred from assignment tests. This approach shows that steep and dry lands can stop, impede or divert the dispersal of a mobile carnivore such as the otter.
\end{abstract}

In recent years, we have witnessed the recovery of previously threatened or endangered species via recolonization of historically occupied areas (Lucchini et al. 2002, Hirzel et al. 2004, Kaphegyi et al. 2006, Vandel et al. 2006). Some of these recolonizations are the result of reintroductions, while others are due to the natural dispersal of individuals. Dispersal is the movement of individuals (usually subadult) away from their place of birth or from a high density population to establish themselves in suitable habitat and reproduce (Ricklefs and Miller 2000, King and
With 2002). With respect to the demographic recovery of species there is a need to monitor contemporary population movements (Manel et al. 2003, 2005) and to identify the factors, such as barriers and corridors, that affect them (Rosenberg et al. 1995). Studies of dispersal and recolonization have clear conservation implications (Clobert et al. 2001), such as developing optimal strategies for replacement of extirpated populations (Schwartz et al. 2007). Although it can be challenging when species movement patterns are cryptic. 
Dispersal and colonization events of elusive species are rarely observed by direct study or survey of spoor (Sutherland 1996). Mark and recapture or telemetry are time consuming, complex with some species (e.g. semiaquatic ones), and can be stress-inducing for the animal (Mech and Barber 2002). Population genetics, and more specifically non-invasive genetic sampling, is therefore a good means of obtaining data on individuals and their movements with minimal disturbance (Coulon et al. 2006, Schwartz et al. 2007). Combined with recent tools in landscape genetics (e.g. Bayesian clustering methods, assignment tests, and isolation by distance; see Manel et al. 2003, 2005 for reviews), this kind of sampling provide a powerful means of understanding a contemporary colonization with regards to habitat features. The field of landscape genetics investigates how landscape and environmental features structure genetic variation at both the population and individual levels (Manel et al. 2003, 2005).

The European otter Lutra lutra was extirpated in many regions during the second half of the 20th century, mainly due to persecution, habitat loss, fragmentation, pollution, and reduced prey availability (White et al. 2003). However, since the late 1980s and the early 1990s, natural recovery has occurred in numerous parts of Europe (Reuther 2004, Rosoux and Green 2004). The presumed causes of the observed recolonizations are the legal protection of the otter in Europe since 1979 (Bern Convention) and 1992 (Habitat Directive), and improved river management that has resulted in an increase in food biomass (Chanin 2003).

Two juxtaposing factors affect the movements of species across landscapes: dispersal corridors (i.e. the suitable landscape elements that provide for survivorship and movement between different habitats; Rosenberg et al. 1995) and potential barriers. Semi-aquatic and usually nocturnal, the movements of otters are poorly documented. Telemetry has demonstrated that individuals follow rivers within their home range for up to $50 \mathrm{~km}$ in an evening (Erlinge 1967, Chanin 2003). Occasional direct observations, and snow tracking, have shown that otters also move overland (Erlinge 1967, Kruuk 1995). However, the paucity of direct dispersal data on otters means that our understanding of the role of catchment structure and possible barriers like ridges on recolonization patterns remains an important management question.

The main aim of this work is to understand how hydrographic catchments (i.e. basins) delineated by water divides (i.e. ridges), affect population genetic structure and the dispersal of individuals in a contemporary colonization context (i.e. within the few last generations). European otter movements have previously been addressed at 2 spatial and temporal levels: the home-range or seasonal level (Erlinge 1967, Kruuk
1995, Saavedra 2002, Hung et al. 2004, Prigioni et al. 2005) and the global level, through the analysis of the long-term spatial genetic structure of populations (Cassens et al. 2000, Dallas et al. 2002, Randi et al. 2003). Our approach lies between these 2 levels and aims at identifying the spatial features that structure an expanding population over the last few generations at the basin level. We focused on the Cévennes National Park (CNP), near the southern border of the otter recolonization front in France (Fig. 1a and c). Otters began to recolonize this area during the 1980s (Fonderflick et al. 1995) and the entire CNP river network was occupied in 2005 (Janssens et al. 2006).

Specifically, we address 3 questions: 1 ) how are otter populations genetically structured in the CNP? 2) To what extent do the basins and their ridges explain this structure? 3) Do the basins and their ridges affect the spatial colonization process (i.e. the individual movements of recent generation colonizers)?

\section{Materials and methods}

\section{Study area}

The study area consisted of 10 hydrographic basins in the CNP (mean $(\overline{\mathrm{X}})$ area per basin \pm standard deviation $(S D)=480 \pm 190 \mathrm{~km}^{2}$; Fig. 1a and c). The length of permanent watercourses in each basin varies from 50 to $300 \mathrm{~km}(\bar{X} \pm S D=170 \pm 85 \mathrm{~km}$; IGN 1995). Five basins (West) flow into the Atlantic Ocean through the Garonne River; the other five (East) are tributaries either of the Hérault River or of the Rhône River flowing into the Mediterranean Sea. The watercourse distance between the Tarn and the Lot basins is ca $800 \mathrm{~km}$, whereas it is only 150 to $200 \mathrm{~km}$ between the Chassezac, the Ceze, and the Gardon basins. Slopes in the region vary from 0 to $49.9^{\circ}$ (Fig. $1 \mathrm{~b} ; \overline{\mathrm{X}} \pm \mathrm{sd}=7.1 \pm$ $6.7^{\circ}$; altitude ranges from 200 to $1699 \mathrm{~m}$ ). These data were estimated from the Digital Elevation Model of the NASA SRTM data, with a $100 \mathrm{~m}$ resolution grid of slopes using ArcGIS 9.1 (ESRI). Most of the slopes in the Atlantic basins are gentle and consist of marsh or peat bog areas, whereas they are steep in the Mediterranean basins. The lower Tarn (called Tarn2 for distinction) and the Jonte River are separated from adjacent basins by deep gorges. Except ridges, potential physical barriers to otters, such as high dams, waterfalls, highways, big cities, or heavy water pollution sources were absent from the study area.

\section{Non-invasive sampling}

\section{Sampling}

A total of 160 otter spraints (i.e. faeces) were collected in January 2004 and from January to March 2005 at 120 sampling points located along the main rivers 

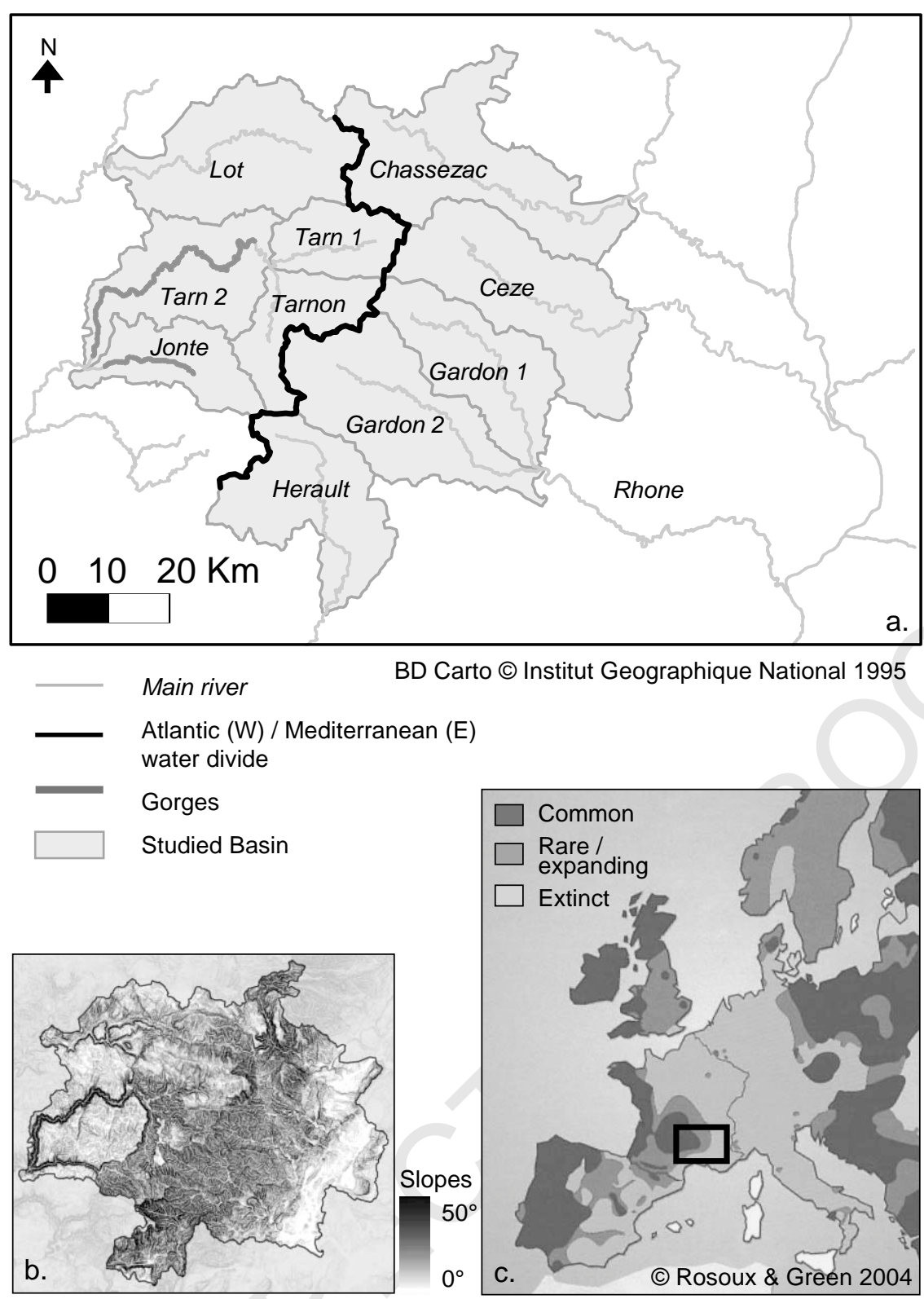

Fig. 1. Study area: (a) hydrography, (b) slopes from a Digital Elevation Model of the NASA SRTM data (with a $100 \mathrm{~m}$ resolution grid of slopes), and (c) location in the context of the otter recovery map in Europe (Rosoux and Green 2004).

within the 10 basins of the CNP (Fig. 2). The sampling points were homogeneously distributed $(5-10 \mathrm{~km}$ apart from each other) with a similar sampling effort in the different basins. Since the life expectancy of otters varies between 6 and 9 yr (Hauer et al. 2002), we assumed that the population sampled in 2004 was roughly the same as the one sampled in 2005. To collect fresh material (i.e. from the previous night), sampling points were checked for 2 to 6 consecutive mornings. Spraints were immediately stored in plastic tubes filled with $20 \mathrm{ml}$ of $97 \%$ ethanol, placed in fridge-box ice until the end of the daily trip, and then frozen at $20^{\circ} \mathrm{C}$ (Dallas et al. 2003).

\section{DNA extraction}

Extractions were carried out in April-May 2004 and June 2005 in a DNA-free room. Gloves and aerosolresistant pipette tips were used in all manipulations and negative controls were included in each extraction to monitor contamination. About 200 to $300 \mathrm{mg}$ of scat material from each spraint were placed in sterile $2 \mathrm{ml}$ 

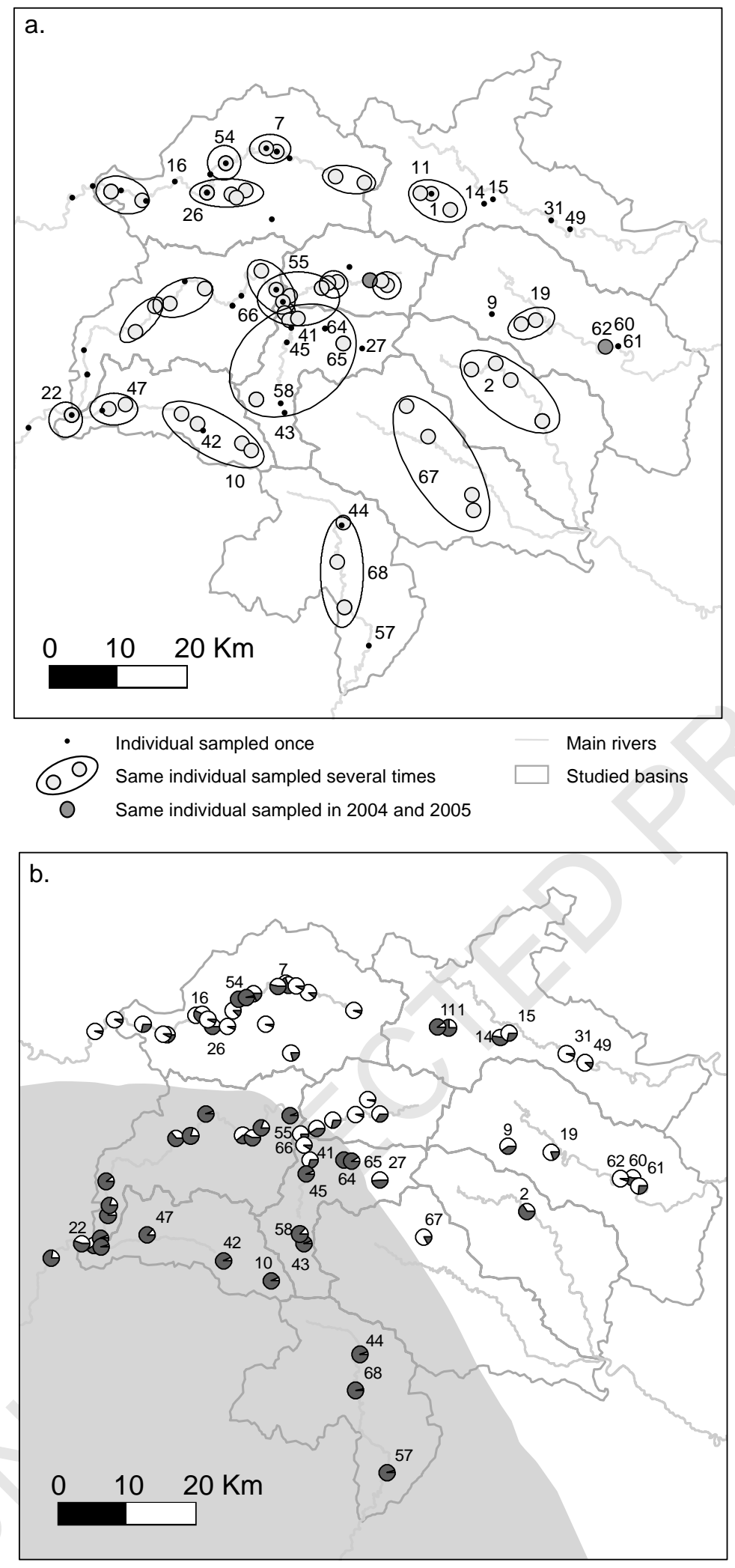

Fig. 2 (Continued) 
microcentrifuge tubes. Supernatant ethanol was evaporated in a rotating dryer system with integrated vacuum pump (DNA Speed Vac) for $30 \mathrm{~min}$. Perforated parafilm membranes covered the tubes to avoid aerosol cross-contamination during the drying step. DNA was extracted from faeces using QIAmp ${ }^{\circledR}$ DNA Stool Mini Kit (Qiagen) following the manufacturer's instructions.

\section{DNA amplification}

On the basis of polymorphism ascertained in a preliminary study (unpubl.), we selected 9 microsatellite loci for this study: Lut 435, 604, 701, 715, 717, 733, 782, 818, and 832 (Dallas and Piertney 1998, Dallas et al. 1999). Each individual was sexed using a SRY sex-typing system (Dallas et al. 2000). All 9 microsatellite loci + SRY were simultaneously amplified by Polymerase Chain Reaction (PCR) using a QIAGEN ${ }^{\circledR}$ Multiplex PCR kit, following the manufacturer's instructions $(50 \mu \mathrm{l}$ volume, $4 \mu \mathrm{l}$ of template DNA, $5 \mu$ of $10 \times$ Primer Mix containing each primer at $2 \mu \mathrm{M}, 25 \mu \mathrm{l}$ of Master Mix, which included a "hotstart" Taq DNA polymerase, dNTPs, and $3 \mathrm{mM}$ of $\mathrm{MgCl}_{2}$ as the final concentration). One primer of each pair was labelled with a fluorescent dye (6-FAM, HEX or NED). PCRs were performed on an ABI thermal cycler with an initial denaturation of $15 \mathrm{~min}$ at $95^{\circ} \mathrm{C}, 40$ cycles at $94^{\circ} \mathrm{C}$ for $30 \mathrm{~s}, 60^{\circ} \mathrm{C}$ for $3 \mathrm{~min}$, and $72^{\circ} \mathrm{C}$ for $60 \mathrm{~s}$, followed by a final extension step at $60^{\circ} \mathrm{C}$ for $30 \mathrm{~min}$. PCR products were genotyped on an ABI310 sequencer (Applied Biosystems). GeneMapper 3.7 was used to score the alleles. All PCRs were prepared under a flow hood in a room physically separated from post-PCR experiments. The plates were irradiated with ultraviolet (UV) light for $20 \mathrm{~min}$ before experiments. All reagents were tested for contamination by including PCR negative controls.

\section{Quality control protocol}

A multi-tube approach was used to limit bias due to allelic dropout and false alleles (Taberlet et al. 1996, Waits and Paetkau 2005). A heterozygous genotype was confirmed after 2 independent observations of the same 2 alleles and a homozygous genotype after 4 independent observations of a single allele (Gagneux et al. 1997). Positive amplifications were repeated up to 8 times in cases of very similar genotypes (one or 2 allele difference). As some multiplex PCRs were positive for some loci but negative for others, samples were amplified from 4 to 40 times $(\overline{\mathrm{X}} \pm S D=16.7 \pm 9.8)$. Forty-three of our 160 samples were discarded due to non-amplification of one locus, after 6 multiplex PCRs, or cross-contamination (2 samples). Similar genotypes independently amplified at least 8 times were considered as unbiased (Taberlet et al. 1996). Our false allele rates and allelic dropout rates were estimated from 0.001 to 0.015 ( $\overline{\mathrm{X}} \pm S D=0.010 \pm 0.005$; number of PCRs $=6633)$ and from 0.45 to 0.65 per locus $(\overline{\mathrm{X}} \pm$ $\mathrm{SD}=0.54 \pm 0.057$; number of PCRs $=3272$ ) respectively. The minimal reliability of consensus genotypes ranges between 0.978 and 0.999 (using equations from Taberlet et al. 1996, Gagneux et al. 1997).

\section{Microsatellite analyses}

Genetic diversity was assessed by measuring observed $\left(\mathrm{H}_{\mathrm{o}}\right)$ and expected $\left(\mathrm{H}_{\mathrm{e}}\right)$ heterozygosity (Nei 1978) and $\mathrm{F}_{\mathrm{IS}}$ values (Weir and Cockerham 1984). Heterozygote deficit, Hardy-Weinberg, and linkage (HWL) disequilibrium were examined using exact tests implemented in GENEPOP 3.4 (Raymond and Rousset 1995, Bonferroni correction applied (Sokal and Rohlf 1998)). The probability that 2 related individuals have the same genotype ( $\mathrm{P}_{\mathrm{ID}}$ sibs) was estimated considering the observed allelic frequency distribution as described in Waits et al. (2001).

Two Bayesian model-based clustering methods STRUCTURE 2.1 (Pritchard et al. 2000, Falush et al. 2003) and GENELAND 2.0.0 (Guillot et al. 2005b) - were used to infer genetic structure based on individual multilocus genotypes and, for the second algorithm, also on individual spatial coordinates. Both methods used Markov Chain Monte Carlo (MCMC) simulations to partition individuals into groups (or clusters) while minimizing HWL disequilibrium.

STRUCTURE analyses were conducted by running a series of independent simulations with different proposal for the number of simulated clusters $(K)$, testing all values from 1 to 5 . Each run used an admixture model with correlated allele frequencies, no prior population information, $3 \times 10^{6}$ iterations after a burn-in of $2 \times 10^{5}$ iterations. Ten replicates of each run were conducted to test for convergence of the MCMCs.

In GENELAND analyses, all parameters (including K) are co-estimated simultaneously by the MCMC algorithm. However, it is necessary to proceed in 2 steps (Guillot et al. 2005a): a first run to infer K, and a second run with $\mathrm{K}$ fixed at the modal value to estimate the other parameters (mainly the assignment of individuals). The first step was replicated 10 times to check for convergence, allowing $\mathrm{K}$ to vary from 1 to 5

Fig. 2. Sampling location of each individual (a) and results from Bayesian clustering analyses (b): pie charts shows the probability that each individual genotype belongs to the NE (white) or SW (black) cluster inferred using STRUCTURE and mode of the posterior probability of belonging to the 2 clusters using GENELAND (the SW cluster is shaded in light grey). ID codes refer to individual samples in Table 3 or mentioned in the text. 
clusters, using a Dirichlet model and the following run parameters: $10^{6}$ MCMC iterations, maximum rate of Poisson process fixed at 100 , maximum number of nuclei in the Poisson-Voronoi tessellation fixed to 250, and an uncertainty associated with the spatial coordinates of $10 \mathrm{~km}$. We inferred the number of clusters $(\mathrm{K})$ from the modal value of $\mathrm{K}$ for these 10 replicates, and then ran the MCMC again 100 times with $\mathrm{K}$ fixed for this value, $5 \times 10^{5}$ MCMC iterations, and the other parameters unchanged. We calculated the mean logarithm of Posterior Probability of the Data (PPD) for each of the 100 runs and selected the 10 with the highest PPD. These 10 runs were then post-processed (with a burn-in of $5 \times 10^{4}$ iterations) to obtain posterior probabilities of population membership for each individual and each pixel of the spatial domain. We finally checked visually for the consistency of results across these 10 runs.

We further investigated the spatial patterns of genetic variation independently of any assumptions of population model, such as HWL equilibrium, using a principal component analysis (PCA). The PCA was conducted with the program PCAGEN 1.2.1 (Goudet: $<$ http://www2.unil.ch/popgen/softwares/pcagen.htm $>$ ) that uses a covariance matrix of microsatellite allele frequencies to ordinate individual multilocus genotypes on the principal component axes.

Migration among basins was inferred using the assignment tests implemented in GENECLASS 2.0 (Piry et al. 2004; Bayesian method of Rannala and Mountain; Monte Carlo resampling; $10^{4}$ individuals simulated; threshold $\mathrm{p}$-value $=0.01$ ). The individuals likely to be migrants were identified using the "detection of first generation migrants" function implemented in GENECLASS 2.0 with the statistic L $=$ L_home/ L_max (and a threshold probability $\geq 0.95$ ), where L_home is the ratio of the likelihood of the individual genotype within the population where the individual has been sampled and L_max the highest likelihood value among all available population samples (Paetkau et al. 2004). To identify migrants from a non-sampled population, we repeated the same analysis, but using $\mathrm{L}=\mathrm{L} \_$home as the statistical criterion (i.e. the likelihood of individual genotypes being immigrant within the whole sampled population; see Piry et al. 2004 for further details). The hypothetical origin of each migrant or colonizer was deduced considering basins as genetic units (i.e. "the source populations"), and using the function "assign population as origin of individuals" in GENECLASS 2.0.

Isolation-by-distance was examined first at the individual level, using the inter-individual Rousset's genetic distance (Rousset 2000) and tested for significant isolation by distance against both Euclidian and river distance for the spatial parameters. At the population level we used the unbiased Nei's genetic distance (Nei 1978) to minimize bias related to small sample sizes (Hardy and Vekemans 2002) and the minimum distance between rivers as the geographic category. Significance of the regression slope was tested by $10^{5}$ random permutations of the geographic distance matrix (similar to a Mantel test) using SPAGeDi 1.2 (Hardy and Vekemans 2002).

To detect the potential effect of ridges on the otter's colonization, we analysed the correlation between the unbiased Nei's genetic distances between adjacent basins and boundaries between clusters with the mean slopes separating these basins. Gardon1 and Gardon2 basins were artificially grouped together to reach a minimal sample size of 2 for estimating genetic distances. The mean slopes were defined as the mean values of all cells of a $100 \mathrm{~m}$ resolution grid of slopes that were located on the line separating 2 basins (i.e. on a ridge). In an attempt to reduce the noise introduced by river connectivity on the relationship between genetic distance and slope, we considered effective ridges only (i.e. the ridges that an otter could not bypass just by swimming), which we defined as the ridges separating rivers that do not join each other at least $200 \mathrm{~km}$ downstream. Confidence intervals $(95 \%$ CI) on the unbiased Nei's genetic distances were calculated by $10^{4}$ bootstrap resampling over loci under the $\mathrm{R}$ statistical software.

\section{Results}

\section{Population diversity}

We successfully genotyped 117 of the 160 samples, resulting in the identification of 70 unique genotypes $(12,4,4,2$, and 1 otters were respectively resampled 1 , 2, 3, 4, and 7 times; Fig. 2a). One to 23 individuals were identified per basin $(\bar{X} \pm S D=7.0 \pm 6.8)$. The overall male to female sex ratio was 4:3. Eleven females were sampled multiple times at different locations ranging from 1.7 to $22.9 \mathrm{~km}$ apart $(\overline{\mathrm{X}} \pm \mathrm{SD}=8.9 \pm$ $7.2 \mathrm{~km}$ ) and multiple samples from 12 males were separated by 1.5 to $41.1 \mathrm{~km}(\overline{\mathrm{X}} \pm S D=16.6 \pm 12.4$ $\mathrm{km})$. Multiple samplings of a same individual occurred along the same river, except for 3 individuals (Fig. 2a).

The probability that 2 related individuals have the same genotype ( $\mathrm{P}_{\mathrm{ID}}$ sibs) was 0.006 , suggesting a very low risk of counting the same individual twice (Appendix). A significant deficit in heterozygotes was detected at 2 loci (Table 1) within the global sampling, suggesting the presence of population structure (i.e. Wahlund effect). Two loci (Lut435 and Lut715) were in significant linkage disequilibrium $(\mathrm{p}<0.001)$, but no change in the results was observed after removing each of these loci. Five individuals had a single private allele that was always present in a heterozygote state. 
Table 1. Genetic diversity at 9 microsatellite loci of European otters sampled in the Cévennes National Park and within the 2 clusters identified in the study. The number of alleles per locus $(A)$, the observed $\left(H_{o}\right)$ and expected $\left(H_{e}\right)$ heterozygosity, and $F_{I S}$ values are provided as well as the test for heterozygote deficit $(*=p<0.05)$.

\begin{tabular}{|c|c|c|c|c|c|c|c|c|c|}
\hline \multirow[t]{2}{*}{ Locus } & \multicolumn{3}{|c|}{ Global sampling $(\mathrm{n}=70)$} & \multicolumn{3}{|c|}{ Southwest cluster $(n=30)$} & \multicolumn{3}{|c|}{ Northeast cluster $(n=40)$} \\
\hline & A & $\mathrm{H}_{\mathrm{o}} / \mathrm{H}_{\mathrm{e}}$ & $\mathrm{F}_{\mathrm{IS}}$ & A & $\mathrm{H}_{\mathrm{o}} / \mathrm{H}_{\mathrm{e}}$ & $F_{I S}$ & A & $\mathrm{H}_{\mathrm{o}} / \mathrm{H}_{\mathrm{e}}$ & $\mathrm{F}_{\mathrm{IS}}$ \\
\hline Lut435 & 6 & $0.54 / 0.49$ & -0.106 & 4 & $0.83 / 0.59$ & -0.424 & 6 & $0.32 / 0.35$ & -0.068 \\
\hline Lut604 & 5 & $0.63 / 0.62$ & -0.011 & 3 & $0.57 / 0.54$ & -0.042 & 5 & $0.68 / 0.66$ & -0.010 \\
\hline Lut701 & 5 & $0.49 / 0.53$ & 0.085 & 4 & $0.47 / 0.44$ & -0.060 & 4 & $0.50 / 0.57$ & 0.132 \\
\hline Lut715 & 3 & $0.37 / 0.49$ & $0.250^{*}$ & 3 & $0.20 / 0.24$ & -0.165 & 2 & $0.50 / 0.48$ & -0.054 \\
\hline Lut717 & 4 & $0.61 / 0.58$ & -0.068 & 4 & $0.73 / 0.63$ & -0.165 & 3 & $0.52 / 0.53$ & 0.018 \\
\hline Lut733 & 3 & $0.66 / 0.65$ & 0.012 & 3 & $0.67 / 0.64$ & -0.048 & 3 & $0.65 / 0.64$ & -0.019 \\
\hline Lut782 & 3 & $0.09 / 0.08$ & -0.031 & 3 & $0.20 / 0.19$ & -0.077 & 1 & - & - \\
\hline Lut818 & 4 & $0.57 / 0.54$ & -0.060 & 2 & $0.40 / 0.40$ & -0.006 & 4 & $0.70 / 0.59$ & -0.181 \\
\hline Lut832 & 3 & $0.54 / 0.65$ & $0.167^{*}$ & 3 & $0.43 / 0.59$ & 0.274 & 3 & $0.62 / 0.66$ & 0.061 \\
\hline Multilocus & 4 & $0.50 / 0.52$ & & 3 & $0.50 / 0.47$ & & 3 & $0.50 / 0.49$ & \\
\hline
\end{tabular}

\section{Population structure}

Clustering simulations with STRUCTURE converged towards the highest posterior probability solution of 2 distinct genetic clusters (Table 2). Each genotype was assigned probabilistically to both clusters with a membership coefficient mapped on the study area according to the sampling location of individuals (Fig. $2 \mathrm{~b})$. The mean distance along the river was used as the coordinate for individuals sampled at several locations along a river $(n=23)$. geneland converged to a similar solution as that of STRUCTURE, with a maximum posterior probability with 2 distinct geographically delimited genetic clusters. The first was composed of the individuals sampled in the northeast part of the CNP (the NE cluster, $\mathrm{n}=40$ ) and the second was composed of the individuals sampled in the southwest part of the CNP (the SW cluster, $\mathrm{n}=30$ ) (Fig. 2b).

Results of the PCA performed on allele frequencies are shown in Fig. 3. The first axis of the PCA captured $23 \%$ of the total inertia contained in the data set and the second axis $17 \%$. Plotting individual genotypes on the first 2 principal components of the PCA (Fig. 3) supported the genetic differentiation between $\mathrm{NE}$ and SW otters of the CNP, as suggested by the model-based clustering analyses. The percent of inertia for the other

Table 2. Results of the clustering simulations performed on individual otter's genotypes using the STRUCTURE algorithm: number of genetic clusters tested $(K)$, logarithms of the estimated probability of data $(\operatorname{Ln} P(X \mid K))$, and the posterior probability of $\mathrm{K}(\mathrm{P}(\mathrm{K} \mid \mathrm{X}))$ as computed in Pritchard and Wen (2004).

\begin{tabular}{lll}
\hline$K$ & $\operatorname{Ln} P(X \mid K)$ & $P(K \mid X)$ \\
\hline 1 & -1142.7 & 0.00 \\
2 & -1085.7 & 0.96 \\
3 & -1088.9 & 0.04 \\
4 & -1102.7 & 0.00 \\
5 & -1155.0 & 0.00 \\
\hline
\end{tabular}

components dropped below $10 \%$. The 2 clusters showed a strong difference in allelic frequencies $\left(\mathrm{F}_{\mathrm{ST}}=0.102\right.$, exact test for population differentiation: $\mathrm{p}<0.0001)$.

\section{Isolation by distance and landscape effect on population structure}

At the individual level, no significant correlation was observed between individual-based genetic distance and

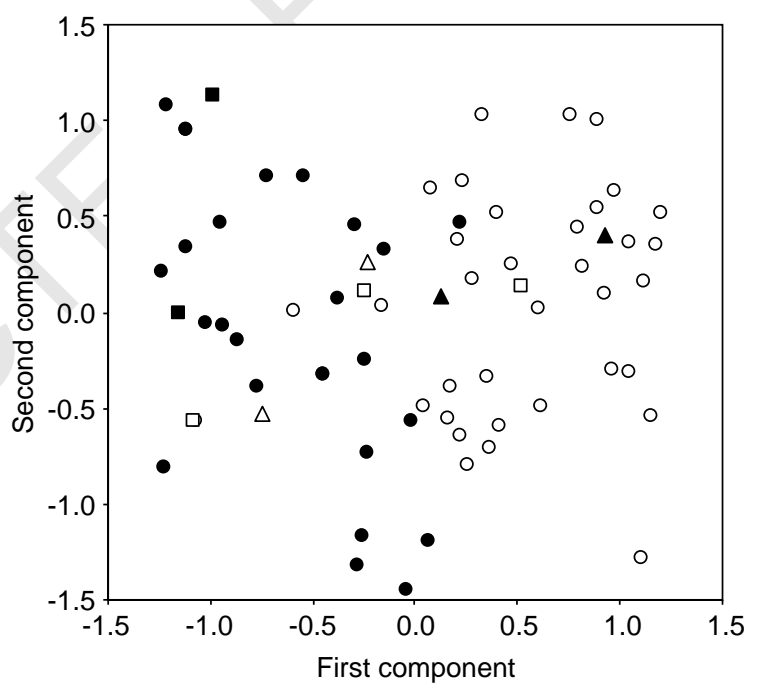

Fig. 3. Principal component analysis (PCA) on mircosatellite allele frequencies. Plot of the individual genotype scores on the first two principal components, which accounted for 23 and $17 \%$ of the variance in the dataset, respectively, and showing the genetic differentiation between the NE (white) and the SW (black) cluster. Triangles refer to individuals that were defined as migrants between NE and SW clusters (Table 3 , ID $=7,11,22,66$ ). Squares refer to individuals that were defined as migrants from outside of the study area (Table 3 , $\mathrm{ID}=16,26,45,54,57)$. 
either measure of geographic distance (i.e. Euclidean or river distances; $\mathrm{p}>0.05$ ). At the population level, there was no direct relationship between the geographical coincidence of the NE and SW clusters with water divides (Fig. 2b). Nor was there a significant correlation between genetic distance and minimum distance between rivers $(p>0.05)$. On the other hand, the unbiased Nei's genetic distance between adjacent basins separated by an effective ridge was positively correlated with the mean slope of the ridge $(r=0.98$; Fig. 4).
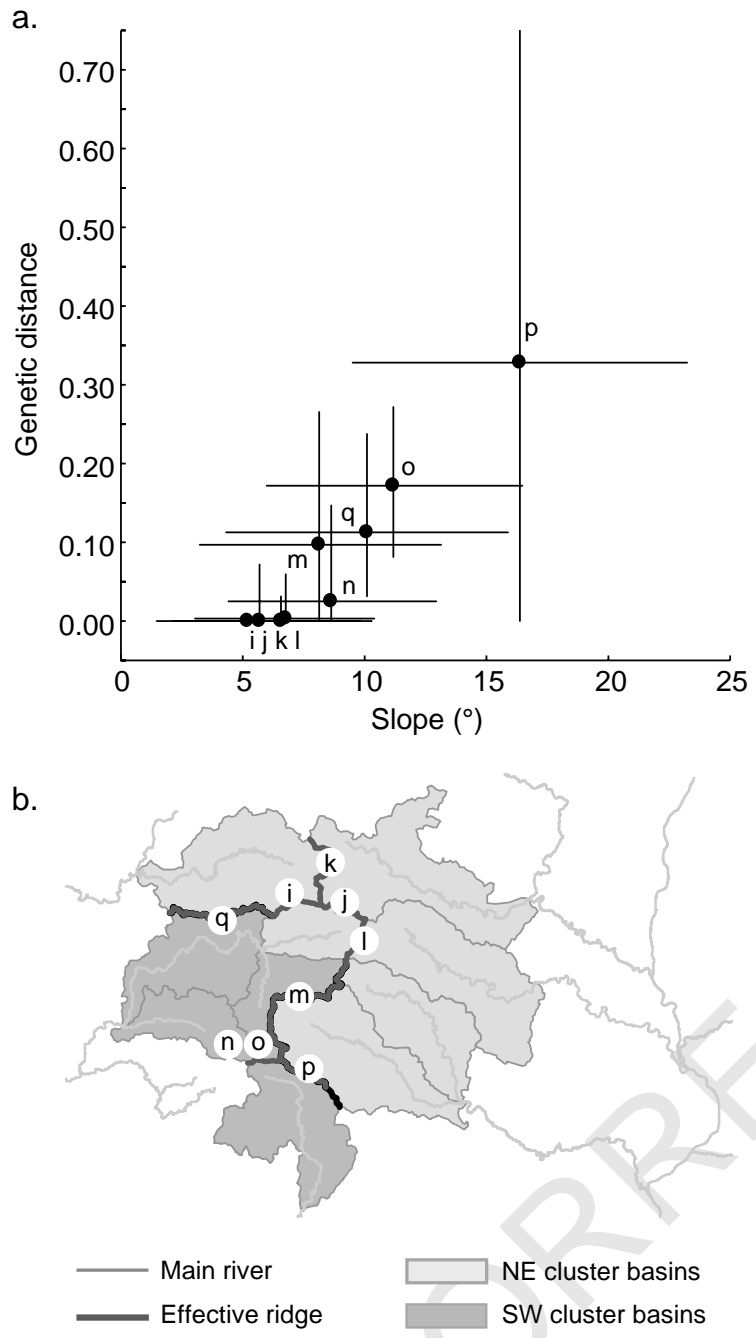

Fig. 4. Effect of inter-basin ridges on the genetic population structure. (a) Mean slope of ridges versus Nei's genetic distance between adjacent basins. Horizontal bars represent \pm 1 standard deviation of the slopes and the vertical bars the $95 \%$ confidence interval of the Nei's genetic distance. (b) Location of the ridges. The mean slope of ridge "q" was computed on a $5 \mathrm{~km}$ buffer area to encompass the Tarn gorges. Gardon 1 and Gardon2 basins were grouped together for the analysis because they contained only one individual each.
However, this relationship has to be interpreted with caution because analyses rely on sub-samples, some of which are very small ( $\mathrm{n}=2$ for some comparisons).

\section{Migration at basin scale and colonization process}

Five types of individual movements were identified based on GENECLASS assignment tests: 1) migration from the SW to the NE cluster, 2) migration from the $\mathrm{NE}$ to the SW cluster, 3) migration from a nonsampled population, 4) colonization of basins inside the SW cluster, and 5) colonization of basins inside the NE cluster (Table 3). Colonizers (types 4 and 5) were defined as all individuals that colonized the study area since 1991, and included individuals sampled along the Tarnon or Jonte rivers and the Hérault, Cèze, Chassezac, Gardon1, and Gardon2 basins, but that were not detected as migrants (types 1 to 3 ). Individuals sampled along the Lot, Tarn1, and Tarn2 rivers (occupied before 1991) were consequently not considered as potential colonizers. The Hérault, Gardon1, and Gardon2 basins were excluded as potential basins of origin as they were colonized less than one generation ago.

About $6 \%$ of individuals sampled in one genetic cluster were identified as migrants from the other cluster $(5 \%$ from the SW to the NE cluster, $7 \%$ in the reverse direction, Table 3). Five individuals sampled in the Lot, Tarnon, and Hérault rivers likely were immigrants from an external non-sampled population. Within the SW genetic cluster, 6 individuals sampled along the Tarnon were identified as migrants from either the Jonte or the Tarn2. Along the Jonte, 3 individuals likely were migrant from the Tarnon or Tarn2. Two individuals sampled along the Hérault likely were coming from the Jonte or the Tarn2. Within the NE cluster, 5 individuals sampled along the Chassezac were identified as migrants from the Lot, the Cèze, or the Tarn1. Five individuals sampled along the Cèze were identified as migrants from the Lot, the Tarn1, or the Chassezac. Individuals sampled along the Gardon1 and Gardon2 were identified as migrants from the Cèze and/or the Chassezac.

\section{Discussion}

\section{Population diversity}

Considering the median value of otter density recently estimated in Europe from previous demographic surveys (i.e. 1 otter per $15 \mathrm{~km}$ of river Chanin 2003), and the total length of permanent rivers in the CNP $(1650 \mathrm{~km})$, the population size can be roughly estimated to be between 70 and 110 individuals. The sex ratio observed in the present study, with $57 \%$ males, is similar to previous observations that range between 
Table 3. Individual migration probability estimated by assignment tests using GENECLASS. The first column shows the five types of individual movements analysed. For each individual identified as a migrant, only the 2 most likely origins were shown. ID refers to Fig. 2b.

\begin{tabular}{|c|c|c|c|c|}
\hline & Individual (ID) & Sex & Sampling location & Basin of origin (probability) \\
\hline \multirow{2}{*}{ (1) Migration from SW to NE cluster } & 11 & M & Chassezac & Jonte (0.638), Tarnon (0.225) \\
\hline & 7 & M & Lot & Tarnon $(0.612)$, Jonte $(0.548)$ \\
\hline \multirow{3}{*}{ (2) Migration from NE to SW cluster } & 22 & $\mathrm{~F}$ & Tarn2 & Lot $(0.922)$, Chassezac $(0.918)$ \\
\hline & 66 & M & Tarnon & Lot $(0.587)$, Chassezac $(0.564)$ \\
\hline & 16 & $\mathrm{~F}$ & & $?(0.994)$ \\
\hline \multirow{7}{*}{ (3) Migration from non-sampled population (?) } & 26 & $\mathrm{~F}$ & Lot & $?(0.976)$ \\
\hline & 54 & M & & $?(0.972)$ \\
\hline & 45 & M & Tarnon & $?(0.990)$ \\
\hline & 57 & M & Hérault & $?(0.990)$ \\
\hline & 43 & $\mathrm{~F}$ & & Jonte (0.455), Tarn2 (0.333) \\
\hline & 27 & M & & Jonte (0.163), Tarn2 (0.157) \\
\hline & 58 & $\mathrm{~F}$ & Tarnon & Tarn2 (0.213), Jonte $(0.118)$ \\
\hline \multirow{12}{*}{ (4) Colonization of basins inside the SW cluster } & 41 & M & & Tarn2 (0.150), Jonte $(0.041)$ \\
\hline & 64 & M & & Tarn2 (0.058), Jonte $(0.025)$ \\
\hline & 65 & $\mathrm{~F}$ & & Tarn2 (0.058), Jonte (0.025) \\
\hline & 10 & M & & Tarnon (0.761), Tarn2 (0.685) \\
\hline & 42 & $\mathrm{~F}$ & Jonte & Tarnon (0.748), Tarn2 (0.362) \\
\hline & 47 & M & & Tarn2 (0.733), Tarnon (0.244) \\
\hline & 68 & M & Hérault & Jonte (0.766), Tarn2 (0.465) \\
\hline & 44 & M & & Tarnon $(0.142)$, Jonte $(0.099)$ \\
\hline & 15 & $\mathrm{~F}$ & & Lot $(0.927)$, Cèze $(0.784)$ \\
\hline & 14 & $\mathrm{~F}$ & & Lot $(0.728)$, Cèze $(0.701)$ \\
\hline & 49 & M & Chassezac & Lot $(0.321)$, Tarn1 $(0.276)$ \\
\hline & 1 & $\mathrm{~F}$ & & Tarn1 (0.305), Lot (0.166) \\
\hline \multirow{8}{*}{ (5) Colonization of basins inside the NE cluster } & 31 & M & & Tarn1 (0.224), Lot (0.169) \\
\hline & 62 & M & & Lot (0.961), Tarn1 (0.769) \\
\hline & 61 & M & & Chassezac $(0.901)$, Lot $(0.901)$ \\
\hline & 60 & M & Cèze & Chassezac $(0.894)$, Lot $(0.837)$ \\
\hline & 9 & $\mathrm{~F}$ & & Chassezac (0.636), Lot $(0.563)$ \\
\hline & 19 & $\mathrm{~F}$ & & Chassezac $(0.407)$, Lot $(0.405)$ \\
\hline & 2 & M & Gardon1 & Cèze (0.784), Chassez. (0.662) \\
\hline & 67 & M & Gardon2 & Chassezac $(0.417)$, Lot $(0.389)$ \\
\hline
\end{tabular}

50 and $61 \%$ males (Hauer et al. 2002, Dallas et al. 2003, Hung et al. 2004). This suggests that both our non-invasive sampling scheme and otter sprainting behaviour were unbiased (Kruuk 1995). If this is true, the sampling of 5 males and no females in the basins at the front of the colonization (i.e. along the Gardons and Hérault rivers) suggests male-biased dispersal. Sexbiased dispersal pattern has already been observed in North American river otters Lontra canadensis (Blundell et al. 2002).

The 70 otter genotypes identified within the CNP showed lower number of alleles per locus and lower heterozygosity than those observed across Europe, and even slightly lower than observations in the west of France $\left(\mathrm{H}_{\mathrm{e}}: 0.71\right.$ in Europe and 0.59 in France, based on 8 microsatellite loci shared by Randi et al. 2003 and the present study). This low genetic diversity is a typical pattern in colonizing animals (e.g. wolverines, Walker et al. 2001; Eurasian lynx, Rueness et al. 2003; Eurasian badgers, Pope et al. 2006). As otters began the colonization of the CNP less than 10 generations ago (Janssens et al. 2006), the patterns of genetic diversity and structure are expected to be strongly influenced by this colonization process. This recolonization is ongoing in the CNP and intermixing is currently occurring with other populations from the Atlantic coast (west of France) (Reuther 2004, Rosoux and Green 2004).

\section{Population structure}

The 2 clustering approaches and the PCA conducted to infer the genetic structure of the otter populations in the CNP led to convergent results. The otter population is organised into 2 distinct genetic clusters with large genetic differences in allelic frequencies (Figs. 1 and 2). This difference between the 2 clusters likely reflects a contact zone between 2 colonizing source populations. The NE cluster extends along the Lot, upper Tarn, and Chassezac rivers. It can be assumed that this cluster is connected with the populations of the northern Massif Central (Fonderflick et al. 1995) where the species survived during the last century (Rosoux and Green 2004). The origin of the SW cluster (Tarn 2, Tarnon, Jonte, and Hérault rivers) is more speculative. The lower Tarn (Tarn 2) could have been colonized 
from southwest populations (Landes or Pyrenees, several-hundred swimming $\mathrm{km}$ downstream). This question may be solved by the analysis of genetic material from these regions.

The genetic boundary observed on the Tarn River between Tarn 1 and Tarn 2 and in the upper Mimente (i.e. neighbouring and connected rivers, Figs. 1 and 2) can be explained by this contact zone hypothesis: colonizers arrived from the NE and SW origins (as described above) at similar periods on both sides of the boundary. These colonizers settled in the basins, but new dispersers from NE origin were hypothetically not able to continue their expansion on the other side of the limit because of the presence of resident otters (i.e. dominant individuals) of SW origin and vice versa (Barbosa et al. 2003). A second but non-exclusive hypothesis may be related to the ecological variation along the Tarn River: the Tarn1 and the upper Mimente are mainly occupied by salmonid fishes that reproduce in winter, while the Tarn2 is mainly occupied by cyprinid fishes that reproduce in spring (Sabatier 1994). Since otter breeding phenology is usually dependant on fish production in terms of biomass and diversity (Kruuk 1995), the mating period could be different between the upper and the lower Tarn, resulting in an absence of interbreeding.

Previous studies at the global scale of the otter range revealed the existence of isolation by distance patterns, suggesting that otter's dispersal is spatially restricted (Cassens et al. 2000, Dallas et al. 2002). However, at the scale of our analysis, we did not detect any significant pattern of isolation by distance in the CNP at either individual or basin level. A possible interpretation of this result is that the scale of the study may be too small in regards to the dispersal of individuals. This lack of significant pattern may also result from the very recent recolonization of the CNP. This further suggests that the genetic structure observed in this study may not have reached migration-drift equilibrium (Hutchison and Templeton 1999). Thus the genetic pattern in the CNP may be much more representative of the colonization pattern than of the dispersal pattern of otters.

\section{Colonization process and landscape impacts}

Fifteen years of sign surveys in the study area have pointed to a putative colonization pattern summarized in Fig. 5 (Janssens et al. 2006). Time series analyses of intensive surveys, performed from 1991 to 2005 with similar methodology and effort yearly, have allowed the history of the recolonization, at the basin scale, to be retraced (Janssens et al. 2006). The Lot and Tarn (upper and lower) rivers were first occupied in 1991. The Tarnon and Ceze rivers were the next to be

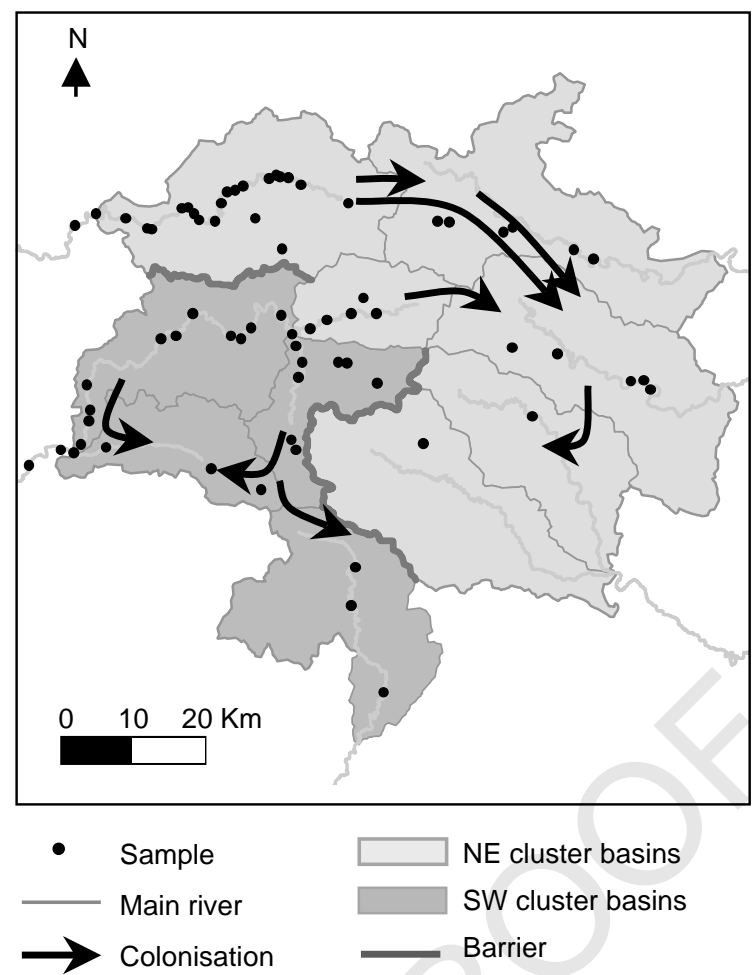

Fig. 5. Inferred colonization directions and barriers based on observed colonization chronology (Janssens et al. 2006), clustering analyses (Fig. 2b), and assignment tests (Table 3).

colonized from 1992 to 1994 . The Chassezac river was colonized from 1995 to 1997 and the Jonte from 1998 to 2000. Finally, the Herault and Gardon rivers were colonized from 2001 to 2003 and in 2005, respectively. Considering the potential origins and directions of colonization inferred from genetic assignment tests (types 4 and 5, Table 3), the probable otter colonization process in the Cévennes is consistent with sign surveys.

We found a positive relationship between the genetic differentiation and the slope of the ridge (Fig. 4). However, this relationship has to be interpreted with caution: first because of the low sample size (as indicated by the large confidence intervals), but also because this relationship confounds intra- and intercluster samples. High genetic distances are driven by the inter-cluster pairs. However, the spatial coincidence of the contact zone with steep ridges (Fig. 4: m, o, p, q; i.e. dry slopes ranging from 8 to $16^{\circ}$ ), and the lack of coincidence in less steep ridges (i, j, k, l), strongly support the hypothesis that the slope of the water divide influences the colonizing ability of otters. Therefore, otters likely were channelled through the ridges i, j, k, and 1 that are occupied by wet areas and are less steep, with mean slopes ranging from 5 to $7^{\circ}$. The crossing of the ridge " $n$ " $\left(8.6^{\circ}\right)$ could have been bypassed via 
another ridge $\left(7.7^{\circ}\right.$ between Dourbie and Hérault rivers) located further south-westwards.

Based on a combination of non-invasive landscape genetics and sign surveys, this study is a clear documentation of the processes involved in the natural recolonization of otters in a semi-montane landscape. Our results showed that the CNP was recolonized by 2 distinct sources of otter populations. However, further work is required to better characterize the contribution of neighbouring populations in the colonization process of the CNP. Landscape elements and in particular the slope of the water divides seem to play a major role in the colonization ability of otters. Steep and dry ridges can impede, divert, or stop the natural expansion of a mobile carnivore such as the otter. Our approach was successful in providing real-time information about otter colonization pattern and process. We believe that these approaches will also be useful in other areas more disturbed by human influences to assess factors that may promote or restrict recolonization (e.g. high dams, waterfalls, highways, big cities, or heavy water pollution sources), providing important information for conservation strategies.

Acknowledgements - For the otter survey and/or the collection of genetic samples, we would like to acknowledge the assistance of the following persons the Cévennes National Park agents and, especially Y. Bruc, S. and B. Descaves, D. Foubert, I and J.P. Malafosse, M. Oziol, S. Pianalto, J. L. Pinna, A. Rival, and J. Seon; the Fisheries Council of France (CSP) with P. Baffie; the ALEPE (Association Lozérienne pour l'étude et la Protection de l'Environnement) with J. Baudat, S. Chazalmartin and A. Jaquet; and finally I. Mercier, S. Marquis, P. Revelli, R. Rosoux, G. Bottin, N. Titeux and M. Bylyna. For their hospitality and advice in laboratory work we would like to thank: M. C. Flamand, E. Mignolet, V. Ducarme, M. Pairon and E. Le Boulengé (Univ. catholique de Louvain); I. Cremasco and A. Vanderpoorten (Univ. de Liège); and A. Ferrando (Univ. Autònoma de Barcelona). This manuscript was greatly improved by the comments of $S$. J. E. Baird, A. Estoup, and 3 anonymous reviewers. Thanks also go to I. Robbins for improved English quality of the manuscript. This work was funded through a National Fund for Scientific Research (Belgium) "research fellow" grant (mandat "Aspirant" FRS-FNRS) to X.J. and M.C.F. and a FRFC fund (Fonds de la Recherche Fondamentale Collective). In memory of X. Domingo-Roura. This is a MARE publication no. 115 .

\section{References}

Barbosa, A. M. et al. 2003. Otter (Lutra lutra) distribution modeling at two resolution scales suited to conservation planning in the Iberian Peninsula. - Biol. Conserv. 114: 377-387.

Blundell, G. M. et al. 2002. Characteristics of sex biased dispersal and gene flow in coastal river otters: implications for natural recolonization of extirpated populations. - Mol. Ecol. 11: 289-303.

Cassens, I. et al. 2000. Mitochondrial DNA variation in the European otter (Lutra lutra) and the use of spatial autocorrelation analysis in conservation. - J. Hered. 91: 31-35.

Chanin, P. R. F. 2003. Ecology of the European otter. Conserving Natura 2000 Rivers Ecology Series No. 10. English Nature, Peterborough.

Clobert, J. et al. 2001. Dispersal. - Oxford Univ. Press.

Coulon, A. et al. 2006. Genetic structure is influenced by landscape features: empirical evidence from a roe deer population. - Mol. Ecol. 15: 1669-1679.

Dallas, J. F. and Piertney, S. B. 1998. Microsatellite primers for the Eurasian otter. - Mol. Ecol. 7: 1248-1251.

Dallas, J. F. et al. 1999. Genetic diversity in the Eurasian otter, Lutra lutra, in Scotland. Evidence from microsatellite polymorphism. - Biol. J. Linn. Soc. 68: 73-86.

Dallas, J. F. et al. 2000. Sex identification of the Eurasian otter Lutra lutra by PCR typing of spraints. - Conserv. Genet. 1: 181-183.

Dallas, J. F. et al. 2002. Spatially restricted gene flow and reduced microsatellite polymorphism in the Eurasian otter Lutra lutra in Britain. - Conserv. Genet. 3: 15-29.

Dallas, J. F. et al. 2003. Similar estimates of population genetic composition and sex ratio derived from carcasses and faeces of Eurasian otter Lutra lutra. - Mol. Ecol. 12: 275-282.

Erlinge, S. 1967. Home range of the otter Lutra lutra L. - Oikos 18: 186-209.

Falush, D. et al. 2003. Inference of population structure using multilocus genotype data: linked loci and correlated allele frequencies. - Genetics 164: 1567-1587.

Fonderflick, J. et al. 1995. Evolution récente du statut de la loutre dans le Parc National des Cévennes. - Cahiers d'Ethologie 15: 233-238.

Gagneux, P. et al. 1997. Microsatellite scoring errors associated with noninvasive genotyping based on nuclear DNA amplified from shed hair. - Mol. Ecol. 6: 861-868.

Guillot, G. et al. 2005a. A spatial statistical model for landscape genetics. - Genetics 170: 1261-1280.

Guillot, G. et al. 2005b. GENELAND: a computer package for landscape genetics. - Mol. Ecol. Not. 5: 712-715.

Hardy, O. J. and Vekemans, X. 2002. SPAGEDi: a versatile computer program to analyse spatial genetic structure at the individual or population levels. - Mol. Ecol. Not. 2: 618-620.

Hauer, S. et al. 2002. Mortality patterns of otters (Lutra lutra) from eastern Germany. - J. Zool. 256: 361-368.

Hirzel, A. H. et al. 2004. Ecological requirements of reintroduced species and the implications for release policy: the case of the bearded vulture. - J. Appl. Ecol. 41: 1103-1116.

Hung, C. M. et al. 2004. Faecal DNA typing to determine the abundance and spatial organisation of otters (Lutra lutra) along two stream systems in Kinmen. - Anim. Conserv. 7: 301-311.

Hutchison, D. W. and Templeton, A. R. 1999. Correlation of pairwise genetic and geographic distance measures: inferring the relative influences of gene flow and drift on the 
distribution of genetic variability. - Evolution 53: 18981914.

IGN 1995. BD Carto (C) Institut Geographique National. - France.

Janssens, X. et al. 2006. The recovery of the otter in the Cevennes (France): a GIS-based model. - Hystrix Italian J. Mammal. 17: 5-14.

Kaphegyi, T. A. M. et al. 2006. Status of the Eurasian lynx $(\operatorname{Lyn} x \operatorname{lyn} x)$ in the Black Forest region, south western Germany. - Mammal. Biol. 71: 172-177.

King, A. W. and With, K. A. 2002. Dispersal success on spatially structured landscapes: when do spatial pattern and dispersal behavior really matter? - Ecol. Modell. 147: 23-39.

Kruuk, H. 1995. Wild otters. Predation and populations. - Oxford Univ. Press.

Lucchini, V. et al. 2002. Non invasive molecular tracking of colonizing wolf (Canis lupus) packs in the western Italian Alps. - Mol. Ecol. 11: 857-868.

Manel, S. et al. 2003. Landscape genetics: combining landscape ecology and population genetics. - Trends Ecol. Evol. 18: 189-197.

Manel, S. et al. 2005. Assignment methods: matching biological questions techniques with appropriate. Trends Ecol. Evol. 20: 136-142.

Mech, L. D. and Barber, S. M. 2002. A critique of wildlife radio-tracking and its use in National Parks. A report to the U.S. National Park Service. - Biological Resources Division, U.S., Geological Survey, Saint Paul, USA.

Nei, M. 1978. Estimation of average heterozygosity and genetic distance from a small number of individuals. - Genetics 89: 583-590.

Paetkau, D. et al. 2004. Genetic assignment methods for the direct, real-time estimation of migration rate: a simulation-based exploration of accuracy and power. - Mol. Ecol. 13: 55-65.

Piry, S. et al. 2004. GENECLASS2: a software for genetic assignment and first-generation migrant detection. - J. Hered. 95: 536-539.

Pope, L. C. et al. 2006. Isolation by distance and gene flow in the Eurasian badger (Meles meles) at both a local and broad scale. - Mol. Ecol. 15: 371-386.

Prigioni, C. et al. 2005. Distribution and sprainting activity of the otter (Lutra lutra) in the Pollino National Park (southern Italy). - Ethol. Ecol. Evol. 17: 171-180.

Pritchard, J. K. and Wen, W. 2004. Documentation for STRUCTURE software version 2. - Dept of Human Genetics, Univ. of Chicago, USA.

Pritchard, J. K. et al. 2000. Inference of population structure using multilocus genotype data. - Genetics 155: 945-959.

Randi, E. et al. 2003. Genetic structure in otter (Lutra lutra) populations in Europe: implications for conservation. - Anim. Conserv. 6: 93-100.

Raymond, M. and Rousset, F. 1995. An exact test for population differentiation. - Evolution 49: 1280-1283.

Download the appendix as file E4936 from <www. oikos.ekol.lu.se/appendix $>$.
Reuther, C. 2004. On the way towards an Otter Habitat Network Europe (OHNE). Method and Results of an Area Assessment on the European and the German Level. - Habitat 15, Hankensbüttel.

Ricklefs, R. E. and Miller, G. L. 2000. Ecology. - W. H. Freeman.

Rosenberg, D. K. et al. 1995. Towards a definition of biological corridor. - In: Bissonette, J. A. and Krausman, P. R. (eds), International Wildlife Management Congress. The Wildlife Society, Bethesda, MD, pp. 436-439.

Rosoux, R. and Green, J. 2004. La loutre. - Belin eds, Paris.

Rousset, F. 2000. Genetic differentiation between individuals. - J. Evol. Biol. 13: 58-62.

Rueness, E. K. et al. 2003. Cryptic population structure in a large, mobile mammalian predator: the Scandinavian lynx. - Mol. Ecol. 12: 2623-2633.

Saavedra, D. 2002. Reintroduction of the Eurasian otter (Lutra lutra) in Muga and Fluvia basins (north-eastern Spain): viability, developement, monitoring and trends of the new population. - Ph. D. thesis, Dept de Ciències Ambientals, Univ. de Girona, Spain.

Sabatier, M. 1994. Cevennes de toutes eaux. - Cévennes 50 52.

Schwartz, M. K. et al. 2007. Genetic monitoring: a promising tool for conservation and management. - Trends Ecol. Evol. 22: 25-33.

Sokal, R. R. and Rohlf, F. J. 1998. Biometry. - W. H. Freeman.

Sutherland, W. J. 1996. Ecological census techniques-a handbook. - Cambridge Univ. Press.

Taberlet, P. et al. 1996. Reliable genotyping of samples with very low DNA quantities using PCR. - Nucleic Acids Res. 24: 3189-3194.

Vandel, J. M. et al. 2006. Reintroduction of the lynx into the Vosges mountain massif: from animal survival and movements to population development. - Biol. Conserv. 131: 370-385.

Waits, L. P. et al. 2001. Estimating the probability of identity among genotypes in natural populations: cautions and guidelines. - Mol. Ecol. 10: 249-256.

Waits, L. P. and Paetkau, D. 2005. Noninvasive genetic sampling tools for wildlife biologists: a review of applications and recommendations for accurate data collection. - J. Wildl. Manage. 69: 1419-1433.

Walker, C. W. et al. 2001. Genetic variation and population structure in Scandinavian wolverine (Gulo gulo) populations. - Mol. Ecol. 10: 53-63.

Weir, B. S. and Cockerham, C. C. 1984. Estimating Fstatistics for the analysis of population structure. - Evolution 38: 1358-1370.

White, P. C. L. et al. 2003. Factors affecting the success of an otter (Lutra lutra) reinforcement programme, as identified by post-translocation monitoring. - Biol. Conserv. 112: 363-371. 